\title{
2000-2017: años dorados y oscuros para la prensa de distribución gratuita en España
}

\author{
2000-2017: golden and dark years for free distribution press in \\ Spain
}

Ana Bellón Rodríguez ana.bellon@usc.es

http://orcid.org/0000-0002-8779-1110

Grupo Novos Medios; Facultad de Ciencias de la Comunicación; Universidad de Santiago de Compostela/ Consejo Superior de Investigaciones Científicas (España)

\section{Resumen}

Los diarios de distribución gratuita, información general y ámbito nacional se convirtieron en España en un fenómeno en el tránsito del siglo XX al XXI. Ese fenómeno, ahora, ha quedado reducido a la mínima expresión. Se acomete un estudio que abarca cerca de dos décadas y se recurre a una metodología cuantitativa amparada en indicadores del Estudio General de Medios e Infoadex. En primer lugar, a partir de la evolución del número de lectores de las cuatro principales cabeceras (i20 minutos, Metro, Qué! y $A D M$ ), se identifican las principales etapas del sector en el mercado español. En segundo lugar, a partir de los indicadores de la evolución de la penetración de medios en España y de inversión en publicidad desde 2000 a 2017, se analizan las causas que lo llevaron a experimentar un período de expansión y otro de 
recesión, prestando atención a si hay una relación entre estas etapas con la evolución de esos indicadores. Hay dos grandes momentos caracterizados por años dorados (2000-2008) y años oscuros (2009-2017) y una relación directa entre esas etapas con el incremento de la penetración del soporte online y el descenso del impreso y los recortes en publicidad, sobre todo, en papel.

Palabras clave: Prensa gratuita; España; expansión; declive.

\section{Abstract}

Free distribution press, general information and nationwide scale became in Spain in a phenomenonin the transit of the XXth century to the XXIth. That phenomenon, now, has been reduced to the minimum expression. We study its evolution that covers two decades. We use a quantitative methodology based on indicators from the Estudio General de Medios and Infoadex. In the first place, based on the evolution of the number of readers of the four main free distribution press (20 minutos, Metro, Qué! and $A D N$ ), the main stages of the sector in the Spanish market are identified. Secondly, based on the indicators of the evolution of media penetration in Spain and investment in advertising from 2000 to 2017, we analyse the causes that led it to experience a period of expansion and another of recession. We pay attention to whether there is a relationship between these stages and the evolution of those indicators. There are two great moments characterized by golden years (2000-2008) and dark years (2009-2017) and a direct relationship between these stages and the increase of the penetration of online support and the decrease of the printed matter and the cuts in advertising, especially on paper.

Keywords: Free press; Spain; expansion; decline.

La prensa de distribución gratuita responde a la misma dinámica que otras empresas de comunicación: combinando los factores de producción, crea mensajes y servicios y los comercializa con el fin de informar, entretener, persuadir y, según algunos tratadistas, educar a sus consumidores para obtener un beneficio (De Mateo, Bergés y Sabater, 2009: 14). Para Nieto e Iglesias:

las empresas promotoras de este modelo de publicación tienen, al igual que otras 
compañías del sector, el cometido de difundir informaciones utilizando medios de comunicación social para conseguir ganancias y alcanzar el poder que se deriva de la actividad empresarial: el de informar (1993: 97).

Sin embargo, el modelo reúne particularidades y singularidades debido, sobre todo, a las innovaciones que aplica en el marketing mix, que entremezcla los cuatro elementos básicos del marketing, los denominados por McCarthy (1960) 4Ps: producto, precio, distribución y promoción.

El producto incluye la oferta tangible. Para Sánchez (2000: 181), los gratuitos poseen "una personalidad propia, con marcas bien definidas" y para Fernández (2003: 56) son "productos pensados para ser leídos de camino al Trabajo". Cuentan con un reducido número de páginas (entre 20 y 24) y ofrecen la información a través de los denominados formatos de lectura rápida, que son definidos por Armentia, Elexgaray y Pérez (1999: 45) como "despieces en los que caben todo tipo de recursos para facilitar la lectura". A estos rasgos se une un diseño muy atractivo con mucho color, contenidos de interés general con un enfoque local y social y ausencia, según proclaman sus promotores, de opinión o tendencia política. Por todo ello, Bakker (2002) considera que se está ante un "nuevo producto informativo". Un nuevo producto informativo hecho por y para la sociedad y los hábitos de vida de los ciudadanos de los primeros años del siglo XXI.

El precio es una herramienta de estímulo de la demanda y un factor determinante de la rentabilidad a alcanzar por la organización (Mad Comunicación, 2007: 37). Los gratuitos rompen en este sentido la dinámica establecida en el sector de las publicaciones periódicas de pago: se entregan sin coste para el potencial lector al financiarse íntegramente con los ingresos publicitarios. Constituyen con esta filosofía, en palabras de Rojo (2008: 56), "la máxima expresión de la cultura del 'todo gratis' que se ha extendido a través de Internet" e introducen, según Santos (2001: 124), "un elemento diferenciador en el mercado de la prensa impresa: el de regalar la publicación".

La promoción engloba, según Kotler et al. (2002: 54), "las distintas actividades que desarrollan las empresas para comunicar los méritos de sus productos y para persuadir a su público objetivo para que compre o consuma ese producto". La prensa gratuita ofrece al anunciante hipersegmentación geográfica (Núñez, 2009). A ello se unen impactantes eslóganes: "El primer diario que no se vende" o "El primer diario hecho por los lectores", por ejemplo, en el caso de 20 minutos.

La distribución, que incluye las diversas actividades que las empresas desarrollan para hacer el producto accesible en el tiempo y lugar al público objetivo (Kotler et al., 2002: 54), es también 
un eje fundamental en este tipo de prensa. Se puede calificar como localizada, personalizada y flexible (Nieto e Iglesias, 1993: 306), pues se realiza en puntos de alta circulación de personas (Flores y Mirón, 2009: 95), a primeras horas de mañana (7 a 10 am), los días laborales y suprimiendo una de las relaciones típicas en la empresa periodística: la relación con el vendedor. Por el tipo de distribución queda claro, además, quién es su público objetivo: gente trabajadora y estudiantes. Se realiza exclusivamente en zonas urbanas y el diario se entrega a mano por parte de repartidores.

En España los diarios de distribución gratuita han sido objeto de investigación en el marco de tesis doctorales (Rubio, 2003; García, 2007; Gironés, 2010; Bellón, 2013; Ávila, 2015). Se han desarrollado líneas de investigación acerca del producto en sí (Casero, 2002; Sabés, 2008), de su impacto en la sociedad española (Santos, 2005; Franco y García, 2009) y en la prensa de pago (Edo, 2005; Sabés, 2006). Se dispone, además, de una radiografía del sector en sus años de máximo esplendor (Vinyals, 2006) y también se le ha prestado atención a su historia (Gómez, 2016).

En el ámbito internacional figuran, entre otros, los trabajos de investigación de Wilcox (2005), Wadbring (2007), Bakker (2013), Tennant (2014) oLamour (2016 y 2017).

\section{Objeto de estudio y metodología}

Tras realizar la revisión bibliográfica correspondiente, se está en condiciones de afirmar que la producción científica sobre la prensa de distribución gratuita en España se ha visto mermada en paralelo a la pérdida de vigor del fenómeno en este país. Además, la investigación académica ha tendido a centrar su atención en un marco temporal de análisis limitado, por lo que se apuesta por examinar el fenómeno de forma longitudinal, teniendo en cuenta las diferentes fases que ha experimentado la prensa gratuita en España.

El fin último, por tanto, es abordar una temática relativamente poco explorada en España sobre un fenómeno comunicacional en decadencia, permitiendo la reflexión y el análisis en cuanto a un tipo de producto impreso, el diario de distribución gratuita, información general y ámbito nacional, que ha finalizado su ciclo de vida de mayor implementación (1).

Se han seleccionado como objeto de estudio las cuatro cabeceras de gratuitos de información general Metro, 20 minutos, Qué! y $A D N$ y el periodo de tiempo de referencia los últimos 17 años (2000-2017) con el fin de indagar en su evolución, acotando para ella las diferenes etapas del sector a partir de hitos en cada cabeceras y de la evolución de sus lectores, y en si ésta tiene o no relación con la de la penetración de medios e inversión publicitaria en España. 
Se opta para ello por una metodología cuantativa que recurre a los indicadores del Estudio general de Medios, para recoger datos de lectores y penetración de medios, y de Infoadex, para indicadores sobre inversión publicitaria.

EI EGM lo elabora la Asociación para la Investigación Medios de Comunicación. Sus orígenes seremontan a la década de los sesenta. A través de 30 mil entrevistas personales face to face al año distribuidas en tres olas, cuyos resultados se conocen en abril, junio y diciembre, el EGM ofrece un retrato sobre el consumo de medios a nivel nacional y autonómico. Se entrevista a la población de 14 años o más, alzando un universo total de más de 30 mil individuos.

InfoAdex es una empresa para el control de la actividad publicitaria en España, tanto a nivel cuantitativo (inversión, inserciones y ocupación) como cualitativo (creatividades). El Estudio InfoAdex de la Inversión Publicitaria en España analiza la inversión real estimada por años por medios, soportes, sectores y anunciantes.

\section{Resultados}

Dos grandes etapas de la prensa gratuita en España: 2000-2008 y 2009-2017

El siguiente gráfico refleja la evolución en cuanto al número de lectores de las cuatro cabeceras. Se aprecian dos grandes momentos: el acontecido entre el 2000 y finales de 2008principios de 2009 y entre 2009 y la actualidad.

La primera fase se caracteriza por un crecimiento constante del número de lectores y la segunda por la tendencia inversa. En el caso de Qué! y $A D N$ las cifras más bajas de lectores coinciden con el momento en el que abandonan el mercado y en ambos casos y en el de 20 minutos las más altas son en 2008, justo cuando el sector toca techo y comienza la crisis económica, como se puede constatar a través de los datos de la tabla. 


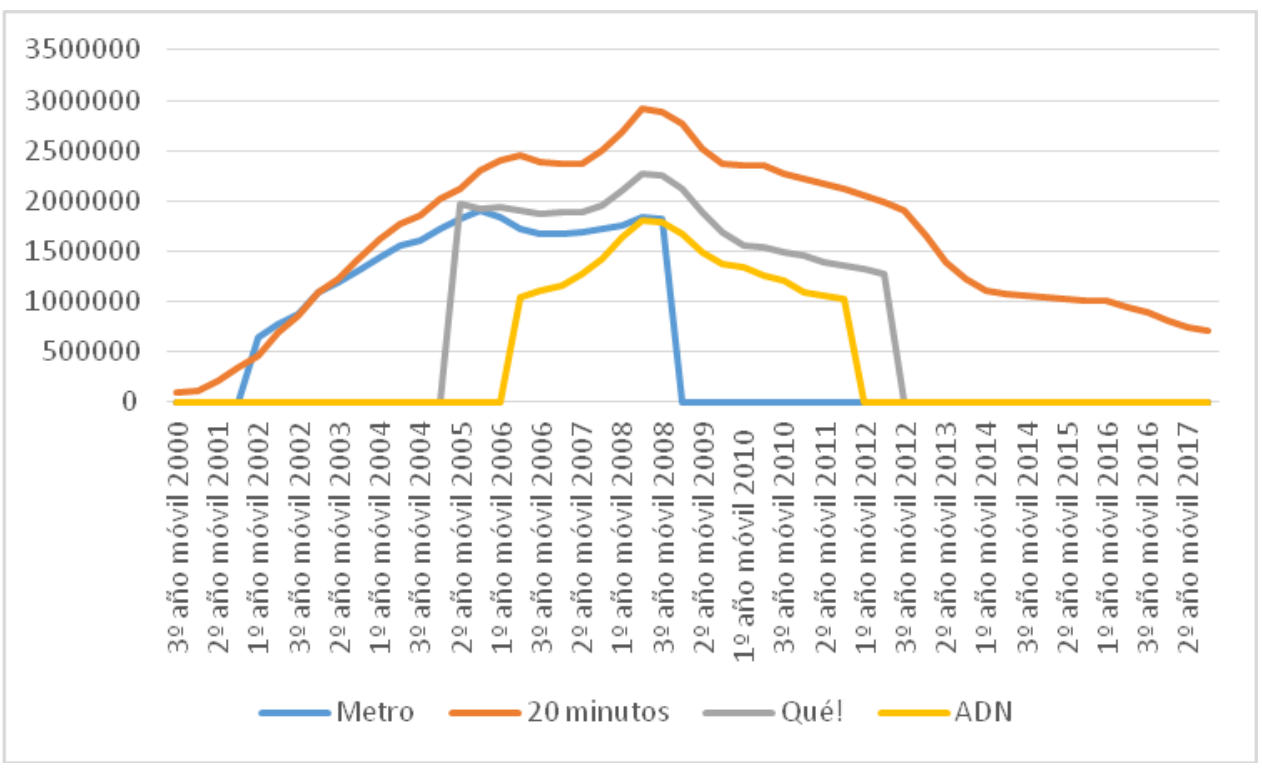

Gráfico 1. Evolución del número de lectores de las cuatro cabeceras (2000-2017).

Fuente: EGM.

\begin{tabular}{|c|c|c|c|c|}
\hline Oleada & Metro & 20 minutos & Qué! & $A D N$ \\
\hline $3^{0}$ año móvil 2000 & & 104.000 & & \\
\hline $1^{0}$ año móvil 2001 & & 116.000 & & \\
\hline $2^{0}$ año móvil 2001 & & 221.000 & & \\
\hline 3ํaño móvil 2001 & & 348.000 & & \\
\hline 1ํ año móvil 2002 & 641.000 & 456.000 & & \\
\hline 2ํaño móvil 2002 & 772.000 & 689.000 & & \\
\hline 3ํaño móvil 2002 & 877.000 & 857.000 & & \\
\hline 1ํaño móvil 2003 & 1.097 .000 & 1.092 .000 & & \\
\hline $2^{0}$ año móvil 2003 & 1.191 .000 & 1.232 .000 & & \\
\hline 3a año móvil 2003 & 1.304 .000 & 1.427 .000 & & \\
\hline 1ำaño móvil 2004 & 1.445 .000 & 1.618 .000 & & \\
\hline $2^{0}$ año móvil 2004 & 1.555 .000 & 1.781 .000 & & \\
\hline 3ํaño móvil 2004 & 1.605 .000 & 1.862 .000 & & \\
\hline 1ำaño móvil 2005 & 1.728 .000 & 2.023 .000 & & \\
\hline $2^{0}$ año móvil 2005 & 1.828 .000 & 2.129 .000 & 1.972 .000 & \\
\hline 3o año móvil 2005 & 1.904 .000 & 2.298 .000 & 1.923 .000 & \\
\hline
\end{tabular}




\begin{tabular}{|l|l|l|l|l|}
\hline 1ํaño móvil 2006 $^{\circ}$ & 1.838 .000 & 2.407 .000 & 1.944 .000 & \\
\hline $2^{\circ}$ año móvil 2006 & 1.721 .000 & 2.448 .000 & 1.900 .000 & 1.047 .000 \\
\hline $3^{\circ}$ año móvil 2006 & 1.675 .000 & 2.379 .000 & 1.876 .000 & 1.115 .000 \\
\hline $1^{\circ}$ año móvil2007 & 1.674 .000 & 2.368 .000 & 1.881 .000 & 1.152 .000 \\
\hline $2^{\circ}$ año móvil 2007 & 1.685 .000 & 2.373 .000 & 1.883 .000 & 1.268 .000 \\
\hline $3^{\circ}$ año móvil 2007 & 1.721 .000 & 2.507 .000 & 1.955 .000 & 1.417 .000 \\
\hline $1^{\circ}$ año móvil2008 & 1.764 .000 & 2.685 .000 & 2.106 .000 & 1.638 .000 \\
\hline $2^{\circ}$ año móvil 2008 & 1.836 .000 & 2.911 .000 & 2.266 .000 & 1.812 .000 \\
\hline $3^{\circ}$ año móvil 2008 & 1.823 .000 & 2.889 .000 & 2.255 .000 & 1.787 .000 \\
\hline
\end{tabular}

Tabla 1. Evolución del número de lectores de las cuatro cabeceras (2000-2008). Fuente: elaboración propia a partir de datos del EGM.

\begin{tabular}{|l|l|l|l|}
\hline Oleada & 20 minutos & Qué! & ADN \\
\hline $1^{\circ}$ año móvil 2009 & 2.772 .000 & 2.116 .000 & 1.671 .000 \\
\hline $2^{\circ}$ año móvil 2009 & 2.527 .000 & 1.885 .000 & 1.495 .000 \\
\hline $3^{\circ}$ año móvil 2009 & 2.376 .000 & 1.698 .000 & 1.381 .000 \\
\hline $1^{\circ}$ año móvil 2010 & 2.353 .000 & 1.563 .000 & 1.341 .000 \\
\hline $2^{\circ}$ año móvil 2010 & 2.347 .000 & 1.547 .000 & 1.261 .000 \\
\hline $3^{\circ}$ año móvil 2010 & 2.279 .000 & 1.496 .000 & 1.203 .000 \\
\hline $1^{\circ}$ año móvil 2011 & 2.222 .000 & 1.464 .000 & 1.097 .000 \\
\hline $2^{\circ}$ año móvil 2011 & 2.171 .000 & 1.398 .000 & 1.064 .000 \\
\hline $3^{\circ}$ año móvil 2011 & 2.120 .000 & 1.360 .000 & 1.024 .000 \\
\hline $1^{\circ}$ año móvil2012 & 2.062 .000 & 1.333 .000 & \\
\hline $2^{\circ}$ año móvil 2012 & 1.986 .000 & 1.269 .000 & \\
\hline $3^{\circ}$ año móvil 2012 & 1.900 .000 & & \\
\hline $1^{\circ}$ año móvil 2013 & 1.661 .000 & & \\
\hline $2^{\circ}$ año móvil 2013 & 1.394 .000 & & \\
\hline $3^{\circ}$ año móvil 2013 & 1.228 .000 & & \\
\hline $1^{\circ}$ año móvil 2014 & 1.102 .000 & & \\
\hline $2^{\circ}$ año móvil 2014 & 1.083 .000 & & \\
\hline $3^{\circ}$ año móvil 2014 & 1.066 .000 & & \\
\hline $1^{\circ}$ año móvil 2015 & 1.040 .000 & & \\
\hline $2^{\circ}$ año móvil 2015 & 1.024 .000 & & \\
\hline $3^{\circ}$ año móvil 2015 & 1.003 .000 & & \\
\hline
\end{tabular}




\begin{tabular}{|l|l|l|l|}
\hline 1ํ año móvil 2016 $^{\circ} 1.00 .9000$ & & \\
\hline $2^{\circ}$ año móvil 2016 & 94.6000 & & \\
\hline $3^{\circ}$ año móvil 2016 & 89.5000 & & \\
\hline 1 año móvil2017 $^{\circ}$ & 812.000 & & \\
\hline $2^{\circ}$ año móvil 2017 & 750.000 & & \\
\hline $3^{\circ}$ año móvil 2017 & 703.000 & & \\
\hline
\end{tabular}

Tabla 2. Evolución del número de lectores de las tres cabeceras (2009-2017). Fuente: elaboración propia a partir de datos del EGM.

La primera etapa se caracteriza por la expansión del modelo de diario gratuito, información general y cobertura nacional. Se inicia en el 2000, con la puesta en marcha de Madrid y m@s, hoy 20 minutos, y concluye en 2009, con el abandono por parte del grupo Metro International del mercado español.

La segunda etapa se define por la recesión y reestructuración del sector. Arranca en 2009, con el abandono del mercado por parte de Metro, y se prolonga hasta nuestros días. En los inicios de esta etapa, las cabeceras de gratuitos pierden lectores, abandonan el mercado y 20 minutos queda en una situación de monopolio, pero fuertemente debilitado. De las tres que desaparecieron Metro lo hizo con cifras de lectores superiores a las de sus inicios, mientras $A D N$ y Qué! lo hicieron con menos que en sus comienzos. 20 minutos, que irrumpió con 104 mil lectores y tuvo su pico de máxima audiencia con 2.911.000, se mantiene como único superviviente con 703.000 lectores, una cifra inferior a la de su entrada en circulación. Las tres cabeceras desaparecieron con cifras de lectores bastante más elevadas que las que tiene en la actualidad 20 minutos.

Se puede hablar, por tanto, de años dorados, que se corresponderían con la primera etapa, y años oscuros, que lo harían con la segunda, para la prensa de distribución gratuita e información general en España. No obstante, conviene hacer referencia a que previamente al lanzamiento de las cuatro cabeceras objeto de estudio se habían puesto en marcha por el Grupo Vocento El Nervión (Bilbao), Qué Pasa (Málaga) y Micalet (Valencia), mientras que el Grupo Zeta había hecho lo propio con Las Crónicas.

Los años dorados comienzan el 3 de febrero del 2000, con la puesta en marcha en Madrid de Madrid y m@s por iniciativa de una empresa española, Multiprensa y más, filial del Grupo Índice Multimedia y entre cuyos accionistas estaban seis cajas de ahorros (Caja de Ávila, Caixa Cataluña, Caja Navarra, Caixanova, El Monte de Sevilla y Caja de Ahorros del Mediterráneo). El 16 de noviembre del 2000 se lanzó una edición para Barcelona. En el verano de 2001 Schibsted Media Group adquirió la mayoría del capital, con lo que el diario cambió de nombre a 
20 minutos y se lanzó a la apertura de delegaciones en las principales ciudades españolas, llegando a contar con 15 ediciones. En paralelo, también puso en marcha su edición online.

Pronto le surgió a 20 minutos un competidor. El 5 de marzo de 2001 Metro International S. A. llega a España. Comienza a distribuirse en Barcelona y establece la misma política expansiva que su homólogo: implanta delegaciones para lanzar su correspondiente edición regional en las ciudades más pobladas. Su edición online no se puso en marcha en paralelo.

La triple oferta vino de la mano de Qué!, lo que marcó un antes y un después al tratarse del primer proyecto gratuito promovido por grupos de comunicación de la prensa de pago. El primer número salió a la calle el 18 de enero de 2005 por iniciativa del Grupo con la participación del Grupo Godó, editor de La Vanguardia. En paralelo, se pusieron en marcha ediciones en las principales ciudades españolas y edición online. El 1 de agosto de 2007 las sociedades Cartera Factoría, S. L. y Grupo Godó de Comunicación S. A. , venden a Vocento el cien por cien del capital de Qué!

El 1 de marzo de 2006 pasará a la historia contemporánea de la prensa de distribución gratuita e información general en España por ser el día en el que el último de los grandes proyectos de este tipo entró en circulación. Se trataba de $A D N$. Estaba, al igual que el diario Qué!, promovido por grupos españoles dedicados a la prensa de pago: Io lideraba Editorial Página Cero S. A. y participaban Planeta, Joly, Promotor Salmantino, Sierra, La Información y La Voz de Galicia. También comenzó su política expansiva a las principales ciudades, en línea con la estrategia seguida por sus competidores, e intentando diferenciarse con temas propios. Asimismo, apostó, al igual que sus competidores, por estar presente en la red con su correspondiente edición online.

En paralelo al inicio de la crisis económica comenzó el cierre de delegaciones y los EREs en los cuatro proyectos. Empezó $A D N$, que en noviembre de 2008 anunció que dejaba de tener delegaciones en La Coruña y Vigo. Surgieron, además, rumores de una posible fusión de Metro y 20 minutos para hacerse más competitivos. Sin embargo, en enero de 2009 Metro International anunció el abandono del mercado español, lo que supuso el primer signo de que el fenómeno, hasta entonces en expansión, había tocado techo, y de que la crisis, con la sucesiva pérdida de ingresos por publicidad, su única fuente de financiación, venía pisando fuerte e iba a dejar huella en el sector.

Así, el 29 de enero de 2009 pasará a la historia contemporánea de la prensa gratuita en España como el día en el que se iniciaron sus años más oscuros. Este periodo, que se prolonga hasta el día de hoy, empieza con el cierre de Metro, debido al "marcado volumen de pérdidas del mercado", y tanto para el diario impreso como para la edición online. La compañía optó, ante una coyuntura negativa, por la decisión más drástica de las que podía adoptar: 
retirada del mercado español siete años después de irrumpir en el mismo.

Le siguieron los cierres de más delegaciones y EREs en los otros proyectos de prensa gratuïta: en marzo de 2009 ADN cerró delegaciones en Sevilla, Málaga, Cádiz y Aragón y procedió a la integración del papel y la web. Mientras, Qué! adoptaba la misma decisión para las ediciones de Mallorca, Muria, Cantabria, Guipúzcoa, Alicante, Vigo y La Coruña. En las restantes ediciones se hicieron ajustes en la plantilla, pasando a denominarse corresponsalías.

Otra estrategia para alcanzar la supervivencia ante la situación que se vivía en Qué! y $A D N$ pasó por reformulaciones de ambos proyectos, sin perder nunca su carácter gratuito. Estos intentos no tuvieron, sin embargo, éxito: el 23 de diciembre de 2011 ADN dejó de salir a la calle y Qué! hizo lo propio el 28 de junio de 2012. ADN cesó su actividad tanto para papel como para web. Qué!, por su parte, cerró su edición impresa, pero mantuvo durante cerca de un año edición online (https://www.que.es/), que en julio de 2013 vendió Vocento a Gestiona Radio.

De la reestructuración del sector ha quedado un solo ejemplo de este modelo de diario, 20 minutos, que sobrevive cinco años después de que su último competidor abandonase el mercado y sin que, por el momento, le surjan homólogos con su misma filosofía: diario en papel con sede central en Madrid y delegaciones en las principales ciudades españolas. El diario continúa en papel con siete (Madrid, Barcelona, Valencia, Sevilla, Málaga, Granada y Córdoba) de las quince ediciones de antaño. En junio de 2015 comenzó una nueva etapa empresarial para 20 minutos: Schibsted vendió sus acciones al Grupo Heraldo de Aragón-Henneo, fundado en Zaragoza en 1895. La operación se enmarcó en el reto de expansión al ámbito nacional a través de una marca ya instaurada y referente en el mercado de la información de acceso libre para el lector y usuario. Heraldo es, a su vez, propietario de un gratuito de ámbito local, Mès (Tarragona).

\section{Relación de las etapas con penetración de medios e ingresos publicitarios}

En paralelo a estos hechos en el sector, la representación en gráfica de la penetración de los diferentes medios en España en este periodo revela que el soporte papel (diarios, suplementos y revistas) ha experimentado un notable descenso a favor del soporte online (internet), mientras que el soporte audiovisual (radio y televisión) se ha mantenido. 


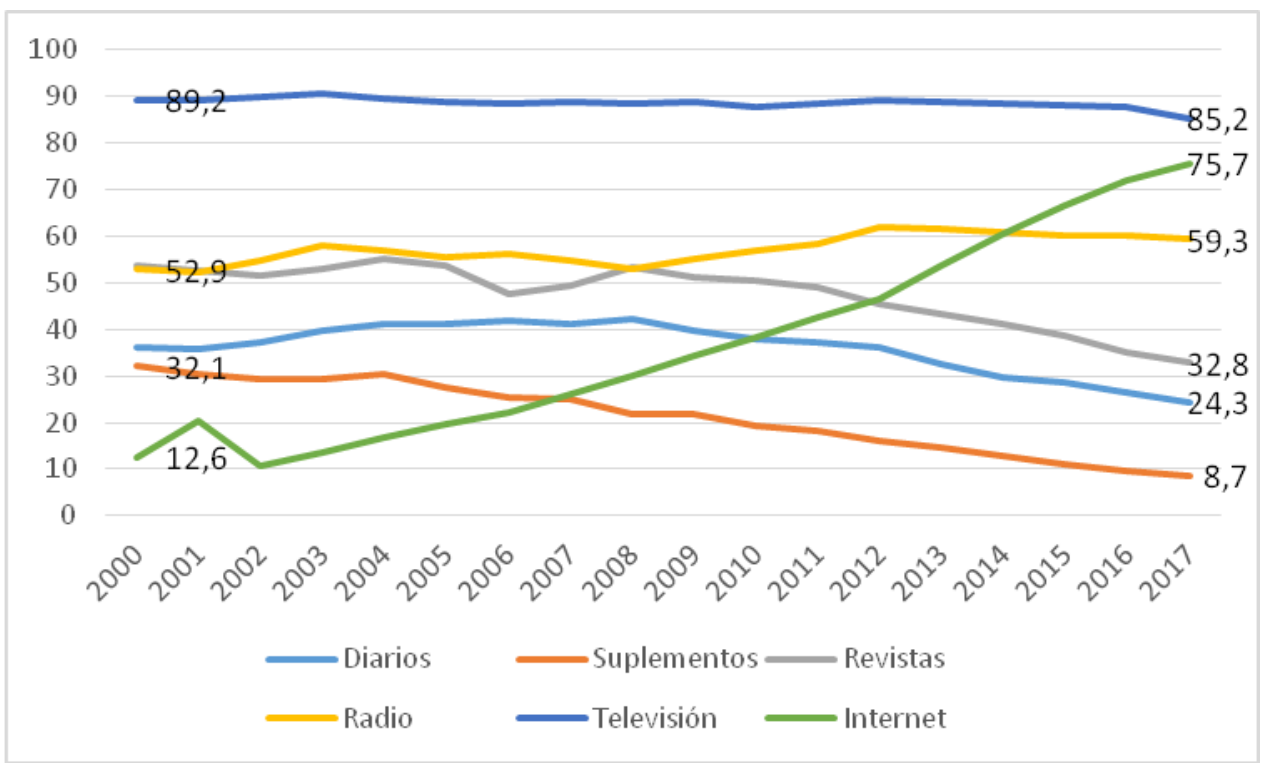

Gráfico 2. Evolución (\%) de la penetración de medios en España (2000-2017). Fuente: EGM.

Tal y como se observa, los diarios incrementaron desde el 2000 hasta 2008 su cuota de penetración en España, lo que coincide, además, con la expansión de la prensa gratuita. En 2009 iniciaron un prolongado descenso, mientras que si hay un medio que sobresale de entre todos por el crecimiento más que exponencial de su nivel de penetración es internet.

A la pérdida de lectores en soporte papel, al descenso de la penetración de los diarios impresos y al ascenso de internet se unió otro factor en el desarrollo de la prensa de distribución gratuita en España: el descenso de las inversiones de publicidad en la prensa, un requisito imprescindible para la viabilidad del modelo de diario de distribución gratuita. En el año 2000, cuando se pusieron en marcha las cabeceras objeto de estudio, se estima que las compañías destinaban a publicitarse en los diarios impresos más de 1 millón y medio de euros. En la actualidad, la cifra supera levemente el medio millón. 


\begin{tabular}{|c|c|c|c|c|c|c|}
\hline Año & Diarios & Dominicales & Internet & Radio & Revistas & Televisión \\
\hline 2000 & 1692,1 & 116,6 & 53,4 & 501,8 & 618,4 & 2274,5 \\
\hline 2001 & 1593,8 & 111,3 & 51,6 & 489,5 & 619,9 & 2096,1 \\
\hline 2002 & 1531,2 & 106,8 & 71,6 & 484,9 & 590,1 & 2172,2 \\
\hline 2003 & 1496 & 105,9 & 74,6 & 508,2 & 601,2 & 2317,2 \\
\hline 2004 & 1583,7 & 110 & 94,4 & 540,2 & 664,3 & 2677,2 \\
\hline 2005 & 1666,4 & 119,3 & 162,4 & 609,9 & 674,6 & 2951,4 \\
\hline 2006 & 1790,5 & 132,2 & 310,4 & 636,7 & 688,1 & 3188,4 \\
\hline 2007 & 1894,4 & 133,5 & 482,4 & 678,1 & 721,8 & 3467 \\
\hline 2008 & 1507,9 & 103,9 & 610 & 641,9 & 617,3 & 3082,4 \\
\hline 2009 & 1174,1 & 68,9 & 654,1 & 537,3 & 401,9 & 2377,8 \\
\hline 2010 & 1124,4 & 72,2 & 798,8 & 548,5 & 397,8 & 2471,9 \\
\hline 2011 & 967 & 67,1 & 899,2 & 524,9 & 381,1 & 2237,2 \\
\hline 2012 & 766,3 & 52 & 880,5 & 453,5 & 313,7 & 1815,3 \\
\hline 2013 & 662,9 & 38,7 & 896,3 & 403,6 & 253,9 & 1703,4 \\
\hline 2014 & 656,3 & 37,7 & 1076,2 & 420,2 & 254,2 & 1890,4 \\
\hline 2015 & 658,9 & 37,8 & 1249,8 & 454,4 & 255,2 & 2011,3 \\
\hline 2016 & 617,4 & 33,8 & 1407,8 & 458 & 252,2 & 2121,9 \\
\hline 2017 & 567,4 & 31 & 1548 & 465 & 240 & 2143 \\
\hline
\end{tabular}

Tabla 3. Evolución de la inversión real estimada en publicidad (en millones de euros) en España (2000-2017). Fuente: Infoadex.

\section{Conclusiones}

Diecisiete años. Ese es el tiempo durante el cual la prensa de distribución gratuita, a través del modelo de diario de información general y cobertura nacional, ha vivido en España tanto su periodo de mayor expansión como de mayor declivie.

La apuesta del sector de la prensa gratuita por el modelo de diario de información general es en España algo más tardía que en el resto de Europa. Bakker (2008) ve los años 1995-2000 como de "implantación" de los gratuitos en este continente en general, mientras que en España no acontecería hasta el periodo 2000-2006.

Divisiones cronológicas al margen, no hay duda de que España ha sido un país paradigmático y de referencia en la historia contemporánea de la prensa gratuita en Europa. En poco más de 
seis años, cuatro cabeceras irrumpieron en el panorama mediático, lo que supuso para la sociedad española el acceso a nuevo modelo de consumo de información en papel. Su implantación trajo consigo también un panorama mediático más amplio, con mayor oferta y mayor competencia en el sector de la prensa tanto por los lectores como por los anunciantes. Ya en 1996 Ruiz y Quintana incidían en que "existe un camino aún por explorar en la prensa gratuita: el de la creación de empresas que unan las potencialidades de este tipo de publicaciones", y eso hicieron en España dos grupos de comunicación internacionales (Metro y Schibsted) y dos grupos de comunicación nacionales (Recoletos y Editorial Página Cero).

Su modelo de gratuito, en línea con la estrategia de marketing mix que seguían en Europa las cabeceras de este tipo, alcanzó cifras de lectores inimaginables en poco tiempo. Eran tiempos en los que la prensa impresa aún no se había visto desplazada como lo está a día de hoy por el soporte online y en los que sus niveles de penetración eran más que aceptables. Los transeúntes, que en la actualidad consultan las últimas noticias en su tablet o en su móvil mientras esperan la llegada del transporte público que los desplazará a su lugar de estudio o trabajo y que seguirán durante el recorrido sin levantar la vista de la pantalla táctil, encontraron, por aquel entonces, una manera sencilla y cómoda de ponerse al día con estos productos impresos.

Ante esos buenos datos de audiencia, y en un contexto de elevadas inversiones publicitarias en la prensa, el modelo se convirtió en un verdadero fenómeno que Edo (2005: 34) enmarcaba en la generalización de internet y sus consecuencias: el público, sobre todo el más joven, no quería pagar por acceder a la información. Paradójicamente, también en la generalización de Internet y sus consecuencias se puede enmarcar su declive: hoy el público, sobre todo el más joven, prefiere el soporte online al papel para consumir información.

Una oferta diaria tan amplia de ese tipo de prensa en un panorama en el que comenzaban a vislumbrarse varias crisis, entre ellas la económica, comenzó a no ser viable y a partir de 2009 el sector inició su particular travesía por el desierto en paralelo a un descenso brutal de su única fuente de oxígeno: los ingresos por publicidad. Comienzan, de este modo, los años oscuros. Abello (2009), considera que "se produjo por una sumatoria de factores de raíz económica y tecnológica".

En los años dorados para el sector la estrategia de las cuatro cabeceras había sido similar: explotar la fórmula de diario gratuito que estaba teniendo éxito en toda Europa a España. Ante la crisis, tres reaccionaron igual: abandonando el mercado. Tan sólo una, 20 minutos, consigue mantenerse a flote, amparada, eso sí, por un variado conglomerado de medios tras sí con nuevas marcas, sobre todo online, que se benefician de la popularidad alcanzada por el papel. Por el camino, además de dejarse millones de lectores, ha cambiado de propietarios y ha 
vuelto a sus orígenes: un grupo de comunicación español.

Los últimos indicadores que pueden ayudar a vislumbrar el futuro del sector no son muy esperanzadores: la inversión publicitaria en diarios continúa en cifras bajas y la prensa sigue perdiendo penetración. No hay noticias de nuevos lanzamientos en el ámbito nacional, si bien conviene permanecer atentos a los movimientos del Grupo Heraldo para las ediciones impresas de 20 minutos o para el lanzamiento de nuevos gratuitos al amparo de esta marca. De lo que no ya no hay duda, tal y como se ha podido confirmar a través de las hipótesis, es de que el impacto de la crisis económica y los cambios en los hábitos de consumo de medios han ido en paralelo a la reestructuración del sector de la prensa de distribución gratuita en España. En la primera etapa la penetración de los diarios inició esta fase con un $36,3 \%$ y la concluyó con un 39,8\%, mientras que la inversión publicitaria en diarios en el año 2000 era de 1.692,1 millones de euros y en 2009 había descendido hasta los 1.174,1 millones de euros. En la segunda etapa se produjo un descenso de la cuota de penetración de audiencia general de los diarios con Internet casi duplicándola y la inversión real estimada de publicidad en prensa descendió cerca de la mitad.

López, Bellón y De Mateo (2014) apuntan que, tras la crisis, los mercados de proximidad aparecen como espacios para iniciativas de diarios de distribución gratuita, y Bellón (2018) ha confirmado esta tesis tomando como referencia una de las 17 Comunidades Autónomas de España, Galicia, donde ha constatado que el sector se ha reinventando apostando por la información local y constituye un soporte con contenidos de interés, por su proximidad para los habitantes de pequeños municipios, y un escaparate para la visibilidad, a través de los anuncios, de las pequeñas y medianas empresas, ayuntamientos y grupos políticos municipales.

Pero ¿podría volver a resurgir el modelo de prensa de distribución gratuita, información general y ámbito nacional en España? ¿podría volver a implantarse algún tipo de modelo de diario gratuito con cobertura nacional en caso de recuperarse las inversiones publicitarias en prensa? En ese caso, ¿qué tipo de gratuito en papel podría tener salida ante los cambios en los hábitos de consumo de información que se han producido y los que, previsiblemente, se producirán? Para dar respuesta a estas y otras preguntes hay que seguir prestando atención a la evolución del sector y, sobre todo, a la de los indicadores que han estado relacionados con su expansión y declive: penetración del soporte impreso e ingresos publicitarios.

\section{Notas}


(1) Entidad financiadora de la investigación: "Usos y preferencias informativas en el nuevo mapa de medios en España: modelos de periodismo para dispositivos móviles" (Referencia: CSO2015-64662-C4-4-R), del Ministerio de Economía y Competitividad. Este proyecto está cofinanciado por el fondo estructural FEDER. Se enmarca además en la Red XESCOM.

\section{Bibliografía}

Abello Banfi, J. (2009). Desafíos éticos del periodismo ante la crisis, tanto de la industria de los medios de comunicación, como la crisis mundial. Seminario Cómo hacer buen periodismo en tiempos de crisis, La Nación, San José, Costa Rica.

Armentia Vizuete, J.; Elexgaray Arias, J. y Pérez Fuentes J. C. (1999). Diseño y periodismo electrónico. Bilbao: Servicio Editorial de la Universidad del País Vasco.

Ávila Rodríguez De Mier, B. (2015). El fenómeno mediático de la prensa gratuita o commuter newspaper en el marco de la sociedad de la información. España: nacimiento, auge, crisis y convergencia (2000-2013). (Tesis Doctoral). Universidad Pontificia de Salamanca.

Bakker, P. (2013). The life cycle of free newspaper business model in newspaper-rich markets. Journalistica, 1, pp. 33-51.

Bakker, P. (2008). The simultaneous rise and fall os free and paid newspapers in Europe. Journalism Practice, 2. Recuperado de http://dx.doi.org/10.1080/17512780802281164

Bakker, P. (2002). Free daily newspapers-business models and strategies. The International Journal of Media Management, 4(3), 180-187.

Bellón Rodríguez, A. (2018). Prensa de distribución gratuita y proximidad en Galicia. El caso de Crónicas da Comarca. Question, 1(58). doi: https://doi.org/10.24215/16696581e045

Bellón Rodríguez, A. (2013). 20 minutos: tres productos y un modelo de redacción. (Tesis Doctoral). Universidad de Santiago de Compostela.

Casero Ripollés, A. (2002). Diarios gratuitos: la calidad informativa en tela de juicio. Revista Latina de Comunicación Social, 50. Recuperado de http://www.ull.es/publicaciones/latina/2002/latina50mayo/5011casero.htm

De Mateo, R., Bergés, L. y Sabater, M. (2009). Gestión de empresas de comunicación. Sevilla: Comunicación Social Ediciones y Publicaciones.

Edo Bolós, C. (2005). El éxito de los gratuitos hace más visible la crisis de la prensa diaria de pago. Estudios sobre el mensaje periodístico, 11, 23-44. 
Fernández, T. (2003). Diarios gratuitos: nuevos diarios que salen del túnel y buscan un lugar en el sol. En Innovaciones en periódicos. Informe Mundial 2003, 54-63.

Franco Álvarez, G. y García Martul, D. (2009). La prensa gratuita generalista en España: un caso de estudio cuantitativo. Ámbitos, 18, 67-82.

Flores Vivar, J. y Mirón López, L. M. (Eds.) (2009). Prensa gratuita y calidad informativa. Innovaciones tecnológicas, retos y perspectivas en los medios gratuitos. Apuntes y propuestas de metodologías y estándares de calidad para un nuevo modelo informativo. Madrid: Ediciones FIEC.

García Jiménez, J. (2007). Gestión de la calidad en la producción de productos de prensa diaria: caso aplicado a 20 minutos. (Tesis Doctoral). Universidad Complutense de Madrid.

Gironés Bolinches, A. (2010). Auge y crisis de la prensa gratuita en Valencia (2007-2009). El caso de mini diario. (Tesis Doctoral). Universidad Miguel Hernández de Elche, España.

Gómez Quijano, A. (2016). La prensa más cara del mundo. Historia de los diarios gratuitos españoles. Madrid: Editorial Fragua.

Kotler, P.; Armstrong, G.; Saunders, J.; Wong, V.; Miquel, S.; Bigné J. E. y Cámara, D. (2002). Introducción al marketing ( $2^{\circ}$ ed. europea). Madrid: Pearson.

Lamour, C. (2017). News for free in the late-modern metropolis: An exploration of differentiated social worlds. Global Media and Communication, 13(3), pp. 213-227.

Lamour, C. (2016). Free dailies in the European cross-border metropolis: The state-based economic deals. International Journal of Communication, 10, 818-837.

López García, X.; Bellón Rodríguez, A. y De Mateo Bergés, R. (2014). Diarios gratuitos atrapados en la crisis: dos formatos diferentes y un destino incierto. Revista Latina de Comunicación Social, 69, 435- 461. doi: 10.4185/RLCS-2014-1019

Mad Comunicación (2007). Todo marketing y más... Fundamentos, principios, conceptos y estrategias. Madrid: FC Editorial.

McCarthy, E. J. (1960). Basic Marketing: A managenerical Approach. Illinois: Irwin.

Nieto, A. y Iglesias, F. (1993). Empresa Informativa. Barcelona: Ariel Comunicación.

Núñez, V. (2009). Guía de publicaciones gratuitas de Madrid. Asociación Española de Prensa Gratuita: Madrid.

Rojo Villada, P. A. (2008). Modelos de negocio y consumo de prensa en el contexto digital. Murcia: Universidad de Murcia Servicio de Publicaciones.

Ruiz, J. y Quintana, C. (1996). Prensa gratuita: á conquista da competitividade. Santiago de Compostela: Edicións Lea. 
Rubio Alonso, V. (2003). Un modelo de financiación: Madrid y m@s. El primer diario que no se vende. (Tesis Doctoral). Facultad de Ciencias de la Información, Universidad Complutense de Madrid.

Sabés Turmo, F. (2008). La prensa gratuita en España: análisis morfológico comparativo de las publicaciones 20 Minutos, Metro, Qué! y ADN. DOXA, 7, pp. 83-108.

Sabés Turmo, F. (2006). ¿La consolidación de los gratuitos amenaza a los diarios de pago? Estudios sobre el Mensaje Periodístico, 12, pp. 235-252.

Santos Díez, M. T. (2005). La prensa gratuita se expande en España. Telos, 63, 13-15.

Santos Díez, M. T. (2001). Los periódicos gratuitos con contenidos especializados en la Comunidad Autónoma Vasca. Revista Ámbitos, 6, 123-142.

Sánchez Tabernero, A. (2000). Dirección estratégica de empresas de comunicación. Madrid: Ediciones Cátedra.

Vinyals, M. (2007). Radiografía de la prensa gratuita. Anàlisi, 35, 239-244.

Wadbring, I. (2007). The Role of Free Dailies in a Segregated Society. Nordicom Review, 28, 135-147.

Wilcox, L. (2005). Metro, info, haro! Fierce reactions to regime competition in the French newspaper industry. Media, Culture \& Society, 27(3), 353-369. 